\title{
Concepciones, conocimientos previos y prácticas en la enseñanza de diseño: un lugar de controversias*
}

Ricardo Chelle**

"El pensamiento apasionado se vincula con el deseo por llegar a lo que todavía no se llegó y a la imaginación, que como parte de la inteligencia nos permite aventurar relaciones y proyectarlas de

manera original".

(Edith Litwin, 2008, p. 29)

\section{Resumen}

Este trabajo, resultado de la investigación realizada para obtener el Master en Educación, se circunscribe a los cursos iniciales de las carreras de Diseño de Interiores y de Arquitectura, tanto las concepciones docentes, como los conocimientos previos de los alumnos y la interacción entre ambos. En él se analiza cómo los buenos docentes consideran dichos conocimientos y qué importancia le asignan al proceso de aprendizaje respecto al resultado. Esta relación entre docentes y alumnos se visualiza dentro de un aula muy especial: "El Taller". Se analiza su historia, el presente y las alternativas que surgen a partir de las nuevas tecnologías. Se destaca la realización de una obra de teatro, teniendo ésta el cometido de sensibilizar la mirada rigurosa del análisis. Se establecen categorías que surgen de la óptica personal, en una investigación que sorprende con resultados inesperados. El conocimiento integral del alumno, el potencial democratizador del taller y la formación del ciudadano, son conclusiones que superan las expectativas iniciales.

\section{Abstract}

The present paper, issued from a research required for the Master Degree in Education, has been limited to beginners' courses on the career of Interior Design and Architecture, and has focused, in particular, on the teachers'concepts as well as on the students' prior knowledge and their interaction. It reveals in which way, the so-called "good" teachers weigh such knowledge and how much importance they bestow to the learning process according to its results. The interaction between teachers and students is conceived within a very specific lesson structure known as "The Workshop". Thus, its history, its present and the new alternatives that may arise by incorporating new technologies are therein analysed. What is worth highlighting is the carrying out of a theatre play with the purpose of sensitising the strict viewpoint of the analytic reader. From said viewpoint different categories would then arise, which, once analysed, shed unexpected and surprising results.

The conclusions drawn from the comprehensive knowledge of the student, the democratising potential of the workshop and the building up of citizens as such, exceeded the initial expectations.

\section{¿Quién? ¿Desde dónde?}

He considerado imprescindible brindar algunas claves para la lectura del presente trabajo, las que ayudarán al lector a situarse en el contexto en el cual aquél fue realizado. Es una mirada personal que se genera tanto de mi experiencia profesional, como de mi experiencia como alumno de arquitectura y como docente de las carreras de Arquitectura y Diseño de Interiores. La docencia me sorprendió dentro de la práctica profesional, dándole a ésta un aire fresco, vital Se abrió una puerta y al traspasarla, el "profesional" descubre un mundo al cual dedicarle 
lo mucho o lo poco, que pueda haber aprendido en su trabajo. También es un mundo del cual aprender, sí, del cual se puede y se debe aprender.

Asumí el desafío de realizar esta Maestría en Educación con el sincero e impostergable afán por aprender., y por obtener, de forma definitiva, el respaldo teórico que me permitiese, en mis desarrollos intuitivos, descubrir mis errores y mis aciertos. Este desafío, que se fue tornando un compromiso irrenunciable, me puso frente a mi primera investigación, al menos, de una investigación con rigor académico. Para quien se consideraba hasta el momento un autodidacta de la docencia, implica un camino nuevo lleno de incertidumbres. Pero luego de los dos años transcurridos, también me acompañaron certidumbres, me acompañaron docentes, compañeros de ruta, amigos. Siento que todos ellos me han dado su apoyo y sin duda todos me han enseñado. Me siento muy agradecido.

Hoy enfrento un nuevo desafío: escribir mi primer artículo. En él trataré de transmitir los puntos que entiendo más trascendentes de la tesis para obtener dicho posgrado. Esto implica un esfuerzo de síntesis, en la cual quedarán muchas palabras sin decir, muchos autores sin ser mencionados. El propósito de este artículo es el de narrar el proceso y los resultados obtenidos en dicha investigación.

\section{Fundamentación}

Resulta necesario debatir sobre uno de los tantos puntos en la compleja relación docente - alumno: la respuesta que da el primero a las ideas previas que tiene el segundo, teniendo especial cuidado en observar los casos en que ellas no coinciden con el estado del arte, con las tendencias del momento. Dicho debate se circunscribirá al área de diseño de las carreras de Arquitectura y Diseño de Interiores, sobre todo en sus cursos iniciales. El estudio se enfocará básicamente desde la perspectiva de la didáctica, sin descuidar la incidencia que tiene en el aprendizaje.

\section{La enseñanza de diseño}

El proceso en la enseñanza de diseño, tanto en Diseño de Interiores como en Arquitectura, no tiene una fórmula única. Por lo general se realizan trabajos, previamente explicados y con un marco teórico propio, que se desarrollan dentro de un aula de características especiales, "El Taller". Dichos trabajos evolucionan con el apoyo del docente, con el intercambio que se produce entre compañeros y sobre todo con el trabajo personal del alumno. Esta evolución se va plasmando en presentaciones sucesivas de menor o mayor formalidad. Las primeras se dan en un vínculo muy estrecho donde el docente cumple un rol similar al de un tutor, realizando sucesivas observaciones que guiarán al alumno en el proceso. En las de mayor formalidad, todo el grupo realiza una entrega general llamada "esquicio". Esto produce un jalón, una fotografía de los logros alcanzados hasta ese momento. Luego de varios esquicios este proceso termina comúnmente con la concreción de los trabajos: "La entrega final". Dichos trabajos por lo general se realizan sobre bases rígidas para ser colgados. Esto permite -a modo de exposición en una galería de arte-, que todos los actores interesados, alumnos, docentes y autoridades institucionales, puedan recorrer los salones y valorarlos.

\section{Intenciones}

Se entiende por "intenciones" a la estructura mental, narrada por el dibujo, que sustenta la concepción del diseño.

El docente debe ser por demás reflexivo con el alumno, deberá escucharlo con atención, preguntar qué quiso hacer y, reflexionando con él en las sucesivas correcciones intentar que reconozca lo que motiva su diseño; que reconozca las intenciones que subyacen detrás de la presentación. 


\section{Intenciones y conocimientos previos}

Se entiende que detrás de las intenciones de diseño está presente la historia del alumno. Cuando promedia la carrera, ya incorporó a su conocimiento distintas corrientes, domina el estado del arte y ha demostrado solvencia para poder resolver distintos problemas de diseño. Pero, ¿qué sucede con el alumno que inicia el proceso, el que cursa primer o segundo semestre? Tiene como referentes de diseño esas casas que le gustan. Las imágenes obtenidas en sus viajes en autobús, la casa de algún amigo o de algún familiar lo han deslumbrado. Sumados a una estufa, un ventanal o una cocina -entre otros referentes-, conforman hasta el momento su catálogo, su conocimiento previo. Tendrá una visión fragmentada, múltiples sinopsis de ejemplos que le gustan. El docente, respetando esa historia previa, tendrá que hacer el esfuerzo de que reconozca el diseño como algo integral. Deberá mostrarle alternativas, abrirle la puerta a otro mundo, uno que todavía no conoce y que tiene que ver con los conocimientos que va adquirir. Es en este momento en el que el alumno comienza un camino de búsqueda, que seguramente no será lineal, que le permitirá ir experimentando con las distintas formas de diseñar. Recorriéndolo irá construyendo su historia.

\section{Intenciones y la esencia del diseño}

Se mencionó anteriormente la importancia que tiene que el alumno reflexione en las intenciones que rigen al diseño presentado. Deberá analizar, a partir de ellas, lo que resulta armonioso y lo que no, asumirlas como guía del trabajo. La mención de las intenciones supone un cierto grado de familiaridad tanto del docente como del alumno con las mismas. Se entiende que es quizá uno de los mayores desafíos que el actual alumno y el futuro profesional, tengan una visión clara de las mismas durante el proceso de proyectación. Visiones externas serán claves para que, con una perspectiva diferente, descontaminada, se ayude al proyectista a ver elementos disonantes con la estructura conceptual planteada por el autor. El alumno inmerso en la resolución de temas menores puede dejar de ver el bosque, la estructura que motivó su diseño.

\section{Intenciones, gusto Vs. proceso}

El alumno, luego de reconocer claramente las intenciones que guían su proyecto, deberá sentir durante todo el proceso, que son suyas, que su autoría no se pierde y que la intervención del docente o de otros alumnos son puntos de vista a aceptar o descartar, para reflexionar y luego actuar. El docente deberá estar atento. Su participación es esperada por el alumno con una gran carga emotiva y tiene gran peso. Una intervención que resuelva el problema sin la reflexión del alumno o una propuesta alternativa fuera de su búsqueda podrán generar una sensación de que está todo mal y frustrarlo. Es ahí donde el docente debe ayudarlo a pensar y a reflexionar sobre lo que hizo. Deberá mantenerse alejado de su gusto personal y de la futura presión de la exposición final del trabajo. No hacerlo le haría perder de vista el objetivo final que es el aprendizaje significativo, el que genere en el alumno un antes y un después, un diferencial que permita ver en qué estado llegó y cómo se fue.

\section{La presión de exponerse}

Esa exposición de trabajos expone al alumno, autor de los mismo, pero también al docente. Es lógico que éste sienta la presión del medio académico. Los logros alcanzados y el criterio de evaluación quedan a la intemperie. Colegas, alumnos y autoridades emitirán opiniones al respecto. El docente, a través de las entregas de sus alumnos, queda expuesto junto a ellos a la mirada de toda la Facultad. Estas entregas no muestran procesos, no explican la evolución del alumno. Nada dicen desde dónde se partió para llegar a ese producto. La presión es real, la mirada externa es fría y mide resultados, los compara con las tendencias y le importa el 
estado del arte. Ante esta situación el docente corre el riesgo de que relativice el proceso de aprendizaje y de que se preocupe más por el producto final, por obtener un resultado exitoso.

¿Existe una contradicción entre lo que se entiende como una buena práctica docente y la aceptación de una entrega final fuera de las tendencias del diseño? ¿Se debe priorizar el proceso de aprendizaje al resultado?

\section{Concepciones y prácticas}

Las concepciones de la enseñanza son posturas basadas en corrientes filosóficas y políticas (entre otras) que inciden en la tarea del docente. La enseñanza a lo largo del tiempo va cambiando y son varios los motivos. Hoy nos encontramos con una "ciencia social", pero la historia muestra otros momentos no tan fermentales. Se puede encontrar a la educación como instrumento del poder, para reafirmar el status quo de la sociedad dominante. Se entiende necesario cuestionar a las concepciones docentes del punto de vista ético. ¿Es la enseñanza en sus distintos niveles una herramienta para democratizar, o por el contrario, para mantener las diferencias sociales ya existentes?

Se entiende como una de las responsabilidades docentes de mayor importancia el tratar de buscar las prácticas que enriquezcan al máximo los actos de enseñar y aprender. Cada docente, en un constante construir de su historia, será receptor de influencias propias de su época y de su contexto. Lo que piense del rol que debe desempeñar y del rol que deben cumplir los alumnos será el resultado de un proceso complejo. Son varias las vertientes que lo nutrirán y seguramente se sienta comprometido con alguna de ellas, hasta quizá se rotule a si mismo como conductista o como constructivista. Puede ser que se pare en una vereda y acuse a la otra, pero seguramente todo docente tenga distintos momentos, inclusive dentro de una misma clase. Cuesta pensar en un docente "puro", si de concepciones se trata. Según Pozo (1996 pp.66 - 67): "A veces, donde las técnicas de aprendizaje asociativo se muestran eficaces, el aprendizaje constructivo no ofrece soluciones claras, o viceversa", seguramente porque las incertidumbres prevalecen sobre las certezas. ¿Cómo se va a dar la próxima clase? Se puede saber cómo empezará, pero no cómo terminará. Una pregunta puede provocar un giro inesperado, y esto está bien. "La enseñanza es similar a otras prácticas que requieren la ejecución de muy diversas actuaciones en tiempo real, en contextos impredecibles y de incertidumbre" (Litwin, E, 2008, p.27).

Pero no todo vale, sobre todo al pensar los alcances de las prácticas. Sin dejar de cumplir con la adquisición de contenidos de la agenda clásica, el docente debe asumir la participación del alumno, no como un espectador, sino como actor. Juntos deben, con el resto de la clase, con el contexto, la familia, los amigos y la comunidad, ir construyendo su conocimiento. Se puede lograr a través de un currículo innovador y haciendo que el alumno participe en la concreción del mismo, dejándolo expresar sus necesidades y que también se involucre con dicha comunidad. Es la búsqueda del alumno comprometido críticamente con la sociedad; es la búsqueda del ciudadano.

\section{Conocimientos previos}

"Si tuviese que reducir toda la psicología educativa a un solo principio, enunciaría éste: de todos los factores que influyen en el aprendizaje, el más importante consiste en lo que el alumno ya sabe. Averígüese esto, y enséñese en consecuencia”, (Ausubel, D., 1983, p.151).

Se puede decir que desde que se nace se empieza a aprender. El ser humano está expuesto a estímulos, a los que va respondiendo, va generando modelos, los que tratarán de ordenar dentro de su cerebro la información recibida. Esos modelos van a ser expuestos o confrontados con una nueva información. Si en esta situación se produce una contradicción, deberá cambiarse el modelo anterior por otro actualizado. Con esto se vuelve a estructurar la base de datos de dicho ser. Estos modelos y su estructura cargada de relaciones, es lo 
que va a conformar su conocimiento, que será previo a la escuela, luego a la secundaria, a la universidad, a los postgrados, etc. En cada momento de cada una de las etapas que acaban de mencionar se se irá avanzando en la construcción del conocimiento. Un conocimiento que ha ido evolucionando, que se ha ido transformando.

El docente no sólo debe saber qué aprendió el alumno, sino qué se transformó dentro de él. Dewey (Jackson, 1986, p. 99) diferencia lo que es el modelo de "reproducción del conocimiento" del de la "transformación del conocimiento". El primero está referido a la acumulación del conocimiento, mientras que el segundo se refiere al aprendizaje significativo. "La mente no es un papel secante que absorbe y retiene en forma automática. Es, antes bien, un organismo vivo que debe buscar alimento que selecciona y rechaza según sus circunstancias y necesidades presentes, y que sólo retiene lo que digiere y convierte en parte de la energía de su propio ser". Lo importante no es qué aprendió el alumno, sino qué cambios recibió en su formación. No sólo interesa qué sabe, sino que esta adquisición de conocimientos lo haya transformado en otra persona, cómo el conocimiento adquirido, según la metáfora de Dewey, por el "organismo vivo" ha sido asimilado, cómo ha incidido en sus conocimientos previos, y por lo tanto, luego del aprendizaje; qué nuevos mapas conceptuales ha concretado para luego aplicarlos en su vida.

\section{Conocimientos previos, inconsciente y memoria, la historia de la vida}

Es importante ir más allá, ILlegar a lo más profundo de su ser. ¿Por qué no a su inconsciente?, sobre todo a lo que Cyrulnik (2007) define como el "inconsciente cognitivo". Deben buscarse estrategias que conduzcan al alumno a reflotar eso que está implícito en su bagaje de conocimientos, pero que él ignora. Se entiende que el manejar sobre un mismo punto distintas visiones abordadas desde distintos ángulos, y si es posible desde distintas disciplinas, puede ser una alternativa para ayudar al alumno a lograr la obtención del conocimiento. Seguramente de lo cotidiano surjan claves si el docente está atento para buscarlas y a encontrarlas. De la experiencia personal se constata que de un simple juego como el ta-te-ti se puede analizar la estructura geométrica del cuadrado. Luego de varias partidas en el pizarrón y solamente con preguntas del docente, los alumnos llegan por sus propios medios a descubrir que el ta-te-ti está inscripto en un cuadrado, que tanto los círculos como las cruces -así como la estructura que los soporta y las diagonales y medianas de la victoria- responden a la estructura interna de dicho cuadrado. Es a partir de ahí que se puede formalizar un conocimiento que estaba en el alumno.

\section{El Taller de Diseño, un lugar de controversias}

Se puede decir que en un título como el de este trabajo, "Concepciones, conocimientos previos y prácticas en la enseñanza de diseño: un lugar de controversias", la mención del lugar no se haría entendiéndolo como un espacio físico, se utilizaría la palabra "lugar" en sentido metafórico, refiriéndose a un espacio de discusión. Pero en este trabajo el lugar es "el taller" y contiene las dos acepciones.

Desde la vivencia personal, el taller se entiende como un aula, donde el intercambio personal encuentra un espacio ideal para su desarrollo. Es un espacio desestructurado, donde se pierde la tensión unidireccional, aquella que va desde el alumno al docente y del docente al alumno. En el taller las relaciones personales se desarrollan en forma de red, en cuyos nodos muchas veces se encuentran los docentes y alumnos en relaciones biunívocas, pero otras tantas se encuentran los alumnos como nodos interconectados Se puede ver a un grupo, concentrado, trabajando, preparándose para una presentación. Por otro lado, a otro grupo en una acalorada discusión sobre algún tema de actualidad que los inquieta; su visión de la arquitectura, la sociedad en crisis, el presupuesto universitario, el fútbol, la música, etc. En algunas facultades, y en algunos tiempos, el taller se caracterizó por ser un espacio de reflexión y de debate, un espacio fermental, testigo de historias personales y colectivas, un marco para el trabajo, 
para la charla, el desarrollo de los afectos, las correcciones, los partidos de ping pong, los de truco, las guitarreadas, las polémicas correcciones, etc. El taller es el hogar académico de los estudiantes. Se sienten contenidos, seguramente felices.

Se entiende este espacio como ideal para la democratización de la enseñanza. Es entonces la responsabilidad del docente, de todo el equipo docente y sobre todo del Director del Taller, del catedrático, explotar al máximo dicho potencial. Debe actuar en la búsqueda de la interacción, tanto vertical como horizontal.

\section{Historia del taller}

Irving Stone en "La agonía y el éxtasis", describe a Miguel Ángel entrando por primera vez en el taller de Ghirlandaio en 1488. Su avidez por aprender se concretaba en una obsesiva búsqueda a través de la copia de los trazos de su maestro, del estudio de los trabajos de sus colaboradores y de la copia de los dibujos de grandes pintores que Ghirlandaio guardaba celosamente, y que Miguel Ángel lograba copiar a escondidas de su maestro. Era a partir de la copia y de los consejos del maestro que el aprendiz lograba adquirir sus conocimientos, no quedando espacio para la crítica. Esta reveladora descripción logra atrapar al lector y llevarlo a la Toscana del Renacimiento, caminar por sus calles, sentarse en la logia florentina, y desde ahí mirar la plaza de la Señoría, ver las esculturas de Donatello y sentir el fuerte olor a pintura del taller de Ghirlandaio.

¿Qué ha pasado cinco siglos después? Seguramente mucho ha cambiado; el mundo es otro. Hoy Florencia se ve atormentada por turistas, las esculturas callejeras, aún erguidas, son bombardeadas por flashes que las convierten en modelos de pasarela. No se necesita sentarse en la logia para ver el Palacio de la Señoría; desde un ordenador doméstico se lo puede ver, saber de su historia, y tener toda la información que se desee y otra que no se pensaba encontrar. Cinco siglos después seguramente los talleres de arte no cambiaron demasiado. Los aprendices buscan maestros, concurren a sus clases, que se dictan por lo general en el mismo lugar de trabajo del artista, les da consejos, trata de que asimilen lo que sabe. Algunos integran la élite del maestro y logran parecérsele. En el mejor de los casos el alumno buscará su propio camino. Y quizá lo encuentre y pueda ser él, con su estilo. Nacerá un nuevo maestro, tendrá sus discípulos y el ciclo vuelve a comenzar.

¿Qué sucedió con el taller a lo largo de la historia, por lo menos de la historia nacional? Se describió el taller de arquitectura desde la experiencia personal, pero ¿qué ocurre con la interacción humana en tiempos donde reina la informática? ¿Qué sucedió con las reuniones en torno a un sulfito, portador de una idea, sobre el cual el docente con su mano experta realizaba trazos estéticamente blandos pero pedagógicamente duros?

\section{Historia del Taller de Arquitectura en Uruguay}

Es relevante para estudiar la historia del taller en Uruguay recurrir al trabajo realizado por el Arquitecto Juan C. Apolo (2006).

En Uruguay, a fines del siglo XIX se crea la carrera de Arquitectura en la Facultad de Matemática, coincidiendo con Ingeniería hasta 1915, año en que se crea la Facultad de Arquitectura. Dicha carrera únicamente se dictó en la Universidad de la República hasta 1999, en que se crea una alternativa, la Facultad de Arquitectura de la Universidad ORT Uruguay. Luego, en 2005 dentro de dicha facultad se crea la primera carrera universitaria de interiorismo, la Licenciatura en Diseño de Interiores. Hoy en día ambas Universidades tienen sin lugar a dudas al diseño como eje central de la enseñanza de dichas carreras, encuentran en el taller de proyecto su espacio natural. Entonces resulta por demás importante analizar la evolución del taller a lo largo de la historia de la enseñanza de la arquitectura en Uruguay.

Con el modelo Beaux-Arts, el rol del taller tiene mucho que ver con el que se mencionó en el Renacimiento. Tiene un fuerte contenido artístico, tanto en el dictado como en el contenido, con 
una fuerte carga decorativa. El primero fue el Taller Carré; luego vendrán Vilamajó y Cravotto, todos destacados profesionales, palabras inapelables, que mantienen con sus alumnos una relación paternal, y todos deben corregirse con ellos. Estos destacados profesionales encarnan el rol del maestro. Esta figura del maestro devendrá, en el Plan 52, en la figura del Director del Taller. Se destaca la figura de Gómez Gavazzo. El taller se hace vertical, en el sentido de que se dictan todos los cursos pasando por todas las temáticas, donde el Director asume su liderazgo. Durante la Intervención la figura de Payssé Reyes pasa a ser fundamental. No sólo se le crea el cargo de coordinador de los talleres, sino que es él quien recibe a los nuevos estudiantes, es él quien les dice que las mujeres no serán buenas arquitectas, si es que logran recibirse. Pero se mantiene la estructura del taller, que continuará después de la Intervención.

Son muchos los talleres que deberían estudiarse, pero para este trabajo el Taller Bayardo adquiere una dimensión de destaque.

\section{El Taller Bayardo}

Es imposible analizar la enseñanza de la arquitectura en Uruguay sin hacer referencia a la figura del Arquitecto Nelson Bayardo. Su amplia carrera como docente en distintos talleres, tanto en Uruguay como en el exterior, se caracterizó por su constante cuestionamiento, tanto de las estructuras, como de la práctica docente. Quizá sea el único investigador sobre la enseñanza de la arquitectura en Uruguay. No se conformó con aceptar que el único requerimiento para el desempeño como docente era certificar el dominio de la disciplina. Puso un especial interés en la formación docente, asumiendo la misma como fundamental dentro de la agenda académica.

En su publicación "Hacia una autodidáctica dirigida" realiza una propuesta pedagógica inédita por el marco teórico en que se apoya. La misma se ubica en un contexto complejo él la entendía como una práctica inmersa en la masificación, aceptando las imposiciones del orden imperante y de la sociedad de consumo. Otro aspecto fundamental de ese contexto es la superpoblación de la Universidad de la República, y en especial de su Facultad de Arquitectura. Le preocupa la masificación, y los resultados de la misma. Entiende que debe cuidarse la libertad de elección, y la forma que sugiere es la de lograr que los alumnos desarrollen un espíritu crítico que les permita cuestionar lo que lo que intenta imponérseles. Es muy gráfico cuando expresa (1990, p. 21): "Esta mentalidad generalizada y anónima, a la que he vinculado con lo que en alguna oportunidad di en llamar el 'pensamiento embotellado' (incapaz de liberarse de los límites impuestos por el envase) deteriora nuestra individualidad a límites insospechados, generando lo que Ortega y Gasset define como el 'hombre-masa', no vinculado a ningún concepto de clase social o económico, sino como conducta asumida por quienes, temerosos de expresarse por sí mismos, se acogen a la seguridad que otorgan los clanes, dando así origen al fenómeno de la masificación, caracterizada esencialmente por la absoluta imposibilidad de cuestionar o cuestionarse en todo aquello que guarde relación con el orden impuesto por la autoridad que le somete, consciente o inconscientemente. Se da en estos ejemplares un sospechoso monolitismo de opiniones y una rigidez que termina haciendo desvanes todo vestigio de inteligencia"

Al hacer referencia al modelo que propone, declara especialmente la relatividad del mismo. Expresa que no debe ser tomado literalmente, sino que debe servir de base de discusión y de futuros hallazgos personales. Propone una enseñanza que debe prescindir al máximo de los maestros y fomentar una mayor independencia del alumno. Define este modelo de enseñanza de la siguiente manera (1990, p.15):

"Autodidáctica es el arte de aprender sin maestros. Autodidáctica Dirigida sería el arte de enseñar con maestros, que deben inculcar en el educando el modo de aprender, prescindiendo al máximo de los maestros, o sea, de ellos mismos. Algo así como el arte, que casi parece un artificio, de que el maestro, estando presente, casi no aparezca, lo que no es fácil para aquellos acostumbrados a ser únicos protagonistas". 
Más adelante aclara que no está haciendo una apología del desempleo. No descarta la presencia del docente, pero sí enfatiza la necesidad del cambio de su rol, así como también hace una apuesta a un nuevo rol del alumno, crítico, no sólo como receptor de contenidos que debe repetir, sino como "artifice de su formación personal". Se entiende que en su propuesta el punto relevante es lo que denomina "La Crítica Indirecta Objetiva" (1990, pp.37-47). La misma aparece como una dimensión de lo que se podría denominar la nueva agenda en la enseñanza de la arquitectura. Cambia el concepto de corrección por el de crítica. Bayardo entiende que hablar de corrección significa referirse a cosas que están mal, a errores cometidos por el alumno que se deben enmendar. En cambio la crítica supone cuestionar y debatir sobre lo realizado, buscando tanto los errores como los aciertos. Sin duda esta postura enriquece el aprendizaje y fortalece la personalidad del alumno. Otro aspecto destacado de la propuesta es la búsqueda de la objetividad, “....por cuanto la crítica que efectúe el docente no deberá traducir la postura personal del mismo frente al tema en discusión, y más allá de que esté inscripta dentro de la doctrina o ideología que el taller sustente..."

\section{El taller virtual}

El avance tecnológico, en especial el aplicado a la comunicación, potencia un nuevo tipo de educación, que de alguna manera puede romper con el concepto tradicional del aula, sobre todo del taller. La nueva interacción se da en un espacio que es virtual. Esto supone la implementación de las Tecnologías de la Información y Comunicación (TICs). Estas nuevas tecnologías han permitido desarrollar una amplia oferta de alternativas pedagógicas.

La diferencia mayor con la enseñanza tradicional es que la separación física que se menciona en el párrafo anterior hace que se modifique la forma de comunicación, con sus pro y sus contras, pero sin duda que es un cambio significativo. Cambia el vínculo entre alumnos y docentes, transformando el espacio físico en virtual. La constante es que los contenidos permanecen iguales, e independientemente de la forma, se trata de enseñar lo mismo. Edith Litwin (2003, p.12) dice: "Sin embargo, el valor de la propuesta, aun cuando adopte los últimos desarrollos de la tecnología, sigue estando, como en cualquier proyecto educativo, en la calidad de los contenidos y en su propuesta para la enseñanza".

Se entiende que plataformas virtuales como Moodle y el mismo Facebook pueden ser alternativas válidas. Ellas pueden aportar un nuevo marco de intercambio, una forma de relacionarse diferente, virtual. Se caracterizan por brindar una estrategia alternativa y complementaria de las clases tradicionales, presenciales. Quizá este medio, que para los docentes -"inmigrantes de la informática" al decir de Prensky- puede resultar ajeno, es, para los estudiantes, es un espacio que le es familiar. Sin duda que la enseñanza de diseño no puede permanecer ajena a esta alternativa. El desafío es cómo implementarla, si es que debe hacerse. Pero no se puede dejar de lado el debate. ¿Es posible un Taller Virtual?

\section{El taller hoy, una experiencia personal}

Desde 1997 soy docente de Taller de Diseño en las carreras de Arquitectura y Diseño de Interiores y durant eeste tiempo muchas cosas han cambiado. Pero desde el año pasado a éste, el cambio cualitativo ha sido enorme. La aparición de los equipos portátiles (laptops, notebooks) y la conexión inalámbrica libre en toda la facultad, modifican radicalmente la geografía del taller. No tengo dudas de que los alumnos, a la vez que trabajaban en sus ordenadores, están conectados chateando, he incluso descargando música. En determinado momento sentí que la clase perdía el rumbo: mientras un grupo hacía una presentación realizada en PowerPoint, otro grupo parecía estar en otro mundo, chateando y riéndose. Mientras seguía la presentación, la que debía corregir, sentía la necesidad de observar la actitud del grupo disperso. Pero en ese momento uno de sus integrantes interviene, haciendo la observación que yo entendía imprescindible. No pude entender lo que pasó hasta que luego de un tiempo, dialogando 
con uno de los alumnos más destacados, le pregunté qué era lo que pasaba con esta nueva forma de trabajo y por qué mientras sucedían cosas que a mi entender era distorsionantes para el dictado de la clase, los resultados eran brillantes. Su respuesta fue la siguiente. "Es que en casa hago lo mismo: mientras trabajo en la máquina, estoy chateando, mirando la tele, y hablando con mis padres".

El desafío está planteado, y entiendo que merece una prolongada reflexión del equipo docente en su conjunto, no debiendo dejar fuera del debate la transmisión de valores. La contemporaneidad nos hace navegar en un mar de incertidumbres, que parece que nunca cesarán de hacernos zozobrar. Al respecto, P. Michael Timpane en la presentación del libro "Enseñanzas Implícitas" (Jackson, 1999, p.12) escribe que lo que a su entender está en la base del pensamiento de Jackson es que: "la enseñanza se funda en la fe y la esperanza y que siempre está un poco más allá de nuestra plena comprensión".

\section{Metodología}

Esta investigación, de corte cualitativo, se basó en un trabajo de campo que se realizó con el apoyo de un conjunto de docentes a quienes se debe rendir tributo por su invalorable colaboración y disposición. La elección de los mismos se realizó con el siguiente criterio: unos fueron seleccionados por los alumnos más destacados de las carreras de Arquitectura y de la Licenciatura en Diseño de Interiores de la Facultad de Arquitectura de la Universidad ORT Uruguay. Otros, por su gran prestigio en el medio académico y profesional. Por último, se seleccionó en base a un criterio personal.

Para la elección de los mejores docentes se realizó una encuesta entre los alumnos que hubieran aprobado el 4 to. semestre en ambas carreras. Debían cumplir con el requisito de tener una escolaridad con un promedio mayor al 90 por ciento del máximo. A ellos se les preguntó cuáles habían sido sus mejores docentes y por qué. Los docentes de alto prestigio se enmarcan en dos ámbitos: el académico y el profesional. Uno es Decano de la Facultad de Arquitectura de la Universidad ORT Uruguay, y el otro es un arquitecto, que si bien dejó la docencia que ejerció en la Facultad de Arquitectura de la Universidad de la República, desarrolla una actividad profesional destacada. Se puede considerar que es uno de los mejores profesionales del medio, con una profunda pasión por el diseño y un gran respeto por la profesión. La elección del mejor docente a nivel personal, el docente memorable, se entendía fundamental. Hasta el momento es un referente constante, un espejo que permitió trabajar en forma intuitiva y luego con otra perspectiva, la que surge del aprendizaje adquirido en el proceso de esta maestría, que se valora aún más.

Todos ellos fueron entrevistados y en uno de los casos se visitó una de sus clases. A la misma llegó como docente que cumplía una suplencia en la clase de otro colega. Luego de realizar el trabajo de campo, se buscaron en cada entrevista dimensiones que se entendieron relevantes u originales en el relato de cada docente. Luego se agruparon las mismas por similitud del tema abordado. Por último se compararon con las obtenidas de los otros docentes tejiendo una red que clarificó los resultados obtenidos, permitiendo su triangulación. De cualquier modo, la relectura de todos los relatos fue agregando momento a momento nuevas dimensiones, muy ricas, quizá por haberse mantenido ocultas entre líneas, lo que las hizo más seductoras. En casi todos los casos, su forma de expresarse y las dimensiones que entienden relevantes de alguna manera se referencian, de un modo más o menos directo, a los puntos de vista de la nueva agenda. La preocupación manifiesta por el aprendizaje significativo, el conocimiento del alumno, etc., nos propone un reto mayor del esperado en la búsqueda de nuevas categorías y en el descubrimiento relaciones que aporten nuevas miradas sobre una vieja temática. 
Realizar una última precisión. Esta investigación se realizó fundamentalmente en la estructura de la Facultad de Arquitectura de la Universidad ORT Uruguay. Es importante decir que su formato de taller se diferencia del de la Universidad de la República, porque los mismos están poblados por integrantes de un único curso, mientras que en la UDELAR se trabaja integrando los distintos niveles a la vez, en el mismo espacio.

\section{El proceso educativo}

Luego de elaborar el marco teórico no caben dudas respecto a la importancia del aprendizaje significativo, del aprendizaje reflexivo al decir de Perkins (2003) y, sobre todo, del proceso frente al resultado: la importancia de la transformación sobre la reproducción del conocimiento, la variación, el delta del aprendizaje, de dónde se partió y adónde se llegó. Se entiende que existe un proceso educativo construido colectivamente por alumnos y docentes. En el mismo se distinguen distintos momentos que van encadenándose. El docente debe conocer al alumno para poder establecer una buena comunicación, procurar que sea constructor de su propio conocimiento y que lo haga en forma reflexiva, que logre establecer distintas miradas, obteniendo distintos puntos de vista sobre un mismo problema, lograr que se motive y que confíe tanto en él, como en sí mismo, para que pueda ir más allá, para que se plantee cada vez metas cada vez más altas, para que se apasione. Y todo esto dentro de un aula especial, el taller.

Luego de realizar el análisis del trabajo de campo se confirma la importancia de lo antedicho. Los docentes entrevistados, desde su lente particular van haciendo énfasis en distintas dimensiones anteriormente mencionadas.

\section{El proceso de Rossana}

Una característica particular de esta tesis fue la elaboración de una obra teatral, que dramatiza la vida del taller, denominada "El Proceso de Rossana". En ella participan actores que tienen mucho que ver con la realidad. De hecho, la realidad nutre muchas veces a la ficción. Esta propuesta es un escenario que reproduce en forma sensible la dureza y el rigor del análisis anterior.

\section{Mirando por el espejo}

En este último tramo se realiza una mirada hacia atrás, hacia los dos capítulos anteriores. Ambos tuvieron una misma guía: el proceso educativo en el espacio del taller. Esta estructura hace al análisis y a la obra de teatro, lo que al proyecto las intenciones de diseño. Con la misma se encontró una plataforma sobre la cual trabajar cada capítulo. Pero ambos encuentran otra mayor, una supra estructura que los articula, que los relaciona: el espejo, un espejo que muestra las dos caras, por un lado, la dura y fría del análisisy por otro la suave y cálida de la obra teatral. La segunda es la que sensibiliza desde el corazón a la razón. Se apela a la emoción, porque no se cree en un diseño que no emocione, y aunque funcione bien, debe conmover, debe buscar sensibilizar a quien lo mire y a quien lo viva. En "El proceso de Rossana" los resultados del análisis cobran vida. El proceso de aprendizaje deja de ser simplemente el hilo conductor de un análisis. Es la narración de la vida universitaria basada en la experiencia de una persona. Tomamos la categoría "narrativa" en el sentido dado por Mac Ewan (1998), es decir, como un lenguaje configurado, como una forma de construcción de sentido que establece una manera de organizar y comunicar historias, contribuyendo a la comprensión de las experiencias que involucran a los seres humanos, y a su vez refiere a la estructura, al conocimiento y a las habilidades necesarias para construir una historia". (Ricobaldi y Ravazzani, 2009).

La investigación cualitativa implica subjetividad, esta subjetividad se refiere a fotos sacadas bajo el lente personal, así como a la historia de los sujetos. Se realizan escenarios. Los mismos narran la realidad del ámbito académico, hasta el punto, que en esta investigación, el escenario 
se transforma en uno físico, teatral. Esta técnica, al decir de Ricobaldi y Ravazzani (2009), supone una forma de reflexionar: "Partimos del supuesto de que dicha construcción es una estructura narrativa que se usa tanto para presentar los resultados de una investigación, como para describir e interpretar las distintas situaciones observadas en un contexto determinado y que de esta manera sirven para explicar y entender distintos fenómenos educativos. Es una estructura potencialmente productora de conocimiento teórico acerca del objeto de estudio y que por tanto puede considerarse una forma de comunicación de los resultados de la investigación educativa". Si bien las autoras plantean el escenario como una alternativa a la elaboración de categorías, igualmente se propone a partir de esta mirada a través del espejo, establecer una relación de ambos capítulos citados para llegar a identificar algunas dimensiones didácticas y transformarlas en categorías, entendiendo a estas últimas como una visión personal de las primeras.

\section{Hallazgos, categorías}

\section{Del ágora a la cancha}

Dos imágenes surgen de este título. Por un lado vemos a un grupo de jóvenes debatiendo junto al maestro Sócrates. Por otro, imaginamos un campo deportivo, una cancha de básquetbol. Los jugadores, integrantes de un equipo, son dirigidos por su entrenador.

Se asocia el Taller al ágora ateniense. Es el espacio democrático por excelencia, ámbito de reflexión, de debate. En este caso, de debate sobre el diseño, sobre la filosofía que lo respalda, sobre política. Es sobre todo un lugar de intercambios personales, en el que se desarrollan afectos entre pares y entre alumnos y docentes, pero donde el diseño siempre está presente, por las mesas con sulfitos, por el par de alumnos que arman su maqueta, por la entrega que quedó colgada en la pared y por muchas cosas más: el diseño es el fin que convoca al ciudadano. Sobre él se centran los debates que se apoyan en la crítica entendiéndola como motor de la reflexión, del aprendizaje, crítica que apunta al producto y al proceso de diseño y nunca a la persona. Resulta imprescindible reforzar el rol de la crítica incluyendo el universo de los aciertos. En el taller se debate sobre lo que está mal, pero también sobre lo que está bien. Se aprende de lo que está bien, incluso sin que el autor haya sido consciente de su acierto. Una reflexión del docente o de un compañero puede advertir al alumno de errores que cometió, pero también reconocer o incluso descubrir sus virtudes. El ágora queda manifiesta, y las opiniones se plantean en un ambiente propicio a realizarlas y a recibirlas. Se ve claramente que para que los logros sucedan los alumnos deben poder expresarse libremente, cumpliendo dos condiciones: el respeto y la objetividad. Y resulta fundamental que el docente cumpla su rol de moderador, valorando la intencionalidad de la crítica y a partir de ella reflexionando, dando luz donde aún existan dudas. El docente deberá cuidar celosamente el espacio democrático, precisando los contenidos de la crítica y moderando la misma.

En "El proceso de Rossana", Marcelo convoca a la clase cuando lo entiende necesario. Mientras está corrigiendo sentado en la mesa con Carlos y Rossana tiene que decirles algo, pero siente que es importante que toda la clase lo escuche. Entiende que es clave, tanto del punto de vista académico como ético. Entonces convoca al grupo. Es cuando plantea la necesidad de la crítica positiva, esa crítica donde todos deben participar. También les dice que son un equipo y que, como tal, deben apoyarse para obtener los mejores resultados, para potenciarse. Se está conectando con el conjunto, está creando una red de caminos, una red de autopistas y puentes. Es la infraestructura que le permite llegar a todas las personas.

Este escenario que aparenta ser teatral puede verse, también, en otro contexto, el deportivo, donde los atletas forman un conjunto que se potencia como tal, con un entrenador que los dirige para alcanzar la meta. Un deporte maravilloso con reglas y sin oponentes, con un entrenamiento basado en la reflexión a partir de la crítica positiva entre iguales y con un director técnico, organizador y moderador, que si se lo permite, puede ser un jugador más sin perder el 
derecho a tener la última palabra, sin perder el rol de conductor. Este entrenador, atento a cada integrante del equipo, se preocupa por conocer sus capacidades para poder sacar del alumno lo mejor de sí, para provecho personal y del equipo, un entrenador que puede comprender que en determinado momento dos de sus jugadores deberán practicar por separado. A partir del conocimiento de ambos entiende que podrán retroalimentarse, para juntos avanzar y volver al equipo y potenciarlo. Resuelve que determinada táctica se arme con la finalidad de destacar las habilidades de un integrante (considerado como uno de los más "apáticos" del grupo) y de esa manera darle un rol protagónico que le permita consolidarse y confiar en sí mismo. Todos los integrantes deberán conocer sus virtudes y defectos, pero por sobre todo deberán entender a este deporte como una tarea colectiva. Son todos piezas de una estructura que sustenta el conocimiento. Es en este contexto que el docente motivador debe estar atento. Constantemente el director técnico debe alentar al atleta cuando logre el acierto o cuando decaiga. El énfasis en el acierto hará que no sólo aumente la confianza en sí mismo, sino que hará que tanto él como el resto del equipo aprendan y entiendan qué se espera de ellos. El aliento en la caída es fundamental para que se sienta contenido; es parte del andamiaje. Es el momento de hacerle ver por qué se falló, qué alternativas hay para resolver la jugada, y de tal forma, todo el equipo aprenderá.

\section{El docente comprometido}

Este docente no se conforma con transmitir los conocimientos, para lo que fue contratado. No se queja de que los alumnos no estudian, ni del bajo nivel conque llegan a facultad. Pero por sobre todo, no ve a los alumnos como una masa uniforme. Él los ve como un conjunto de individualidades, y le preocupan ambas cosas: el conjunto y la persona. Entiende la importancia del colectivo, no como masa, sino como equipo, como una estructura interrelacionada que se puede potenciar exponencialmente. También valora al alumno, no como alguien a quien debe transmitir conocimientos, entiende al alumno con un nombre. No concibe otra forma. Ese nombre implica una vida propia, compleja. La importancia de conocer al alumno se pone de manifiesto: en qué contexto vive, qué conocimientos previos tiene, conocer que lo motiva, sus gustos, sus pasatiempos, conocer cuáles son sus capacidades intelectuales, prácticas, creativas o emocionales (Sternberg, 1997), etc. Este conocimiento permitirá al docente saber qué puertas golpear. Se entiende que se puede ampliar la visión de Ausubel y decir: conózcase al alumno integralmente y actúese en consecuencia.

Sabrá que si no trabajó es porque algo le está ocurriendo. Está al día con su historia personal. Tratará de establecer entre ambos una autopista que los una, la más ancha, con la mayor cantidad de carriles y puentes posibles. Buscará la frecuencia adecuada para la transmisión. Sabrá qué puertas golpear para que el alumno se abra. Aprovechará ese conocimiento del alumno y esa comunicación para que el mismo se sienta bien, para que se motive, para que salga a la búsqueda del conocimiento, de la construcción de su propio conocimiento, porque logró despertarle la curiosidad y que se comprometa con el curso, con su propia formación como profesional.

Es entonces, en "El proceso de Rossana", que aparece la figura de Marcelo, que cumple el rol del docente comprometido. Está atento a lo que pasa con ella. Rápidamente aprende su nombre y cuando ella le pregunta si recuerda su proyecto, se lo describe. Él estudia cómo se viste, percibe si está nerviosa. Luego de saber que canta, otro día sin un sentido aparente, le cuenta que fue a escuchar jazz, y se da cuenta de que este tema los une. Es en este contexto que Marcelo puede empezar su tarea docente. Siente que hizo contacto, Rossana le abrió la puerta, confía en él, le dio el derecho a enseñarle. Pero no solamente le preocupa Rossana; cuando le parece importante su opinión recurre a Carlos. Le pide que critique el proyecto de su compañera. Eso hace que cumpla un rol destacado, otra voz a escuchar. 


\section{El ídolo}

Es muy difícil en un contexto constructivista hablar en forma destacada de un docente que cumpla este rol, un rol que puede asociarse al docente que llega a la clase y se sube a un pedestal, para desde ese plano superior transmitir lo que entiende que los alumnos deben aprender. Sin embargo, se entiende que el ídolo puede representar otra figura, más humana. Quizá por cosas muy simples, porque recuerda sus nombres, conoce sus vidas, sus gustos, sus trabajos. Pero por sobre todo él es el referente, es la figura que se quiere imitar. Se entiende que sabe y que es muy bueno en lo que hace, porque domina la disciplina, porque sabe cómo comunicarse. Es la voz que define una discusión o un proyecto. El docente debe estar en algún momento en ese pedestal y esa distancia debe ser construida por el conocimiento que lo separa del estudiante. El estudiante lo va a colocar allí, porque ese conocimiento, porque ese dominio que tiene de su materia va a generar asombro. De eso él sabe, entonces el alumno lo va a colocar en un pedestal. O sus obras son por demás conocidas, entonces todo el mundo lo reconoce. Tiene que haber instancias de clases magistrales para llevar al estudiante a las bases del conocimiento y que a partir de ahí comience a generar el propio. Es el apoyo, el inicio del camino. El docente en el pedestal se asocia al ídolo, al líder del grupo, liderazgo que surge de la función de referente que debe adquirir. Este rol va a estar siempre en juego. Los estudiantes más críticos desafiarán al docente a demostrar la vigencia del liderazgo. Se entiende que esta tensión ayudará al docente a crecer.

Marcelo cumple ese rol con humildad. No necesita ningún pedestal para ser distinguido. Es su forma de enseñar, es lo que sabe. Cuando explica a Rossana el movimiento del Sol, Carlos se siente deslumbrado por su conocimiento. Hasta el momento sólo había oído del tema, pero no lo comprendía; era una receta. Ahora siente que lo aprendió, valora el conocimiento de Marcelo, se asombra con lo que sabe y cómo lo transmite. Pero es cuando Carlos se entera de que ganó un concurso, que automáticamente lo eleva a su pedestal personal. Ya no es la misma persona, ganó un concurso, percibe que es un profesional destacado, es un ídolo. Cuando Marcelo reflexiona largamente sobre el proyecto de Rossana y tiene la solución, es en ese momento en el que vuelve a aparecer como ídolo. Es el de la voz definitoria, la que concluye con la solución al dilema, la que sugiere cómo seguir. Esa solución no sale de su mano, no busca la copia de un referente, hace reflexionar. Una solución que es de la autoría de Rossana y qué ella muestra por casualidad y en la que él ve un potencial. Le explica por qué esta bien, y que debe cambiar para que mejore. Seguramente, mañana, cuando Rossana sea docente, será como él. No olvidará lo importante que fue para ella que la escuchara, que entendiera cuáles eran sus intenciones y que la ayudara a comprenderlas, que la hiciera reflexionar, incluso oponiéndose a su compañero de cátedra. Este ídolo será para Rossana un docente memorable.

\section{El psicólogo}

A diferencia del punto anterior, al describir a este docente se entiende que se está más cerca de la nueva agenda. Este terapeuta está destinado a cumplir un rol fundamental. Primero, debe hacer que el alumno reconozca su problema, tarea que, en algunos casos, es por demás difícil. Segundo, deberá lograr que actúe en función de ese reconocimiento, de que el alumno acepte y vea qué problema tiene delante. Para que esto ocurra, deberá ganarse su confianza y establecer una buena comunicación; de otra forma no logrará que su paciente acepte hablar. Es a partir de la maduración de este vínculo que va a poderle sugerirle que vea su problema desde otras perspectivas. Seguramente no sean aceptadas en primera instancia. Luego, reflexionando, paso a paso, irá aceptando que ese problema que tanto lo obsesionaba no era insuperable. Cambiando alguna actitud, escuchando, dando la chance a un tercero, era posible resolver ese problema, desatar la madeja que le dificultaba avanzar. Inclusive, puede descubrir una nueva capacidad. La misma le permite que un problema se transforme en algo a su favor. Descubre su inteligencia emocional y comienza a aprovecharla. 
Marcelo intenta que Rossana confíe en él, y para eso trata de conocerla, para establecer una buena vía de comunicación. Cuando siente que ese vínculo está consolidado, que ella le permite opinar, actúa. Y lo hace desde el lado de la reflexión. Intenta que Rossana descubra el origen del problema. Intenta que comprenda. Se propone enseñarle a ver lo importante y que dicha visión se haga desde todos los ángulos posibles. Le muestra distintos caminos que conllevan distintas perspectivas. Le propone que analice el proyecto desde el punto de vista formal, luego de que lo haga desde el punto de vista funcional. También le propone técnicas para poder hacerlo. Pero, por sobre todo trata de que se sienta segura de su vocación. Le expone síntomas que, si reflexiona sobre ellos, la ayudarán a confirmar su interés por la profesión. Prioriza este problema y relativiza el resto. Le pide que no se apresure; paso a paso irá perdiendo las incertidumbres.

\section{Acompañando la subida a la cima}

Como ya se mencionó en este artículo, el alumno llega a la primera corrección de taller con una gran expectativa. Sin conocimientos previos de la materia, la incertidumbre es grande. Se entiende que esta situación genera un gran esfuerzo en el docente para explicar de qué se trata, plantear claramente los objetivos y la metodología a utilizar reforzandolos a lo largo del curso mediante el recuerdo del planteo inicial. El docente debe preocuparse por abordar temas que estén a su alcance y verificarlos en el camino que está iniciando. En el taller el alumno inicia una aventura exploratoria, desconocida, donde se le exige que haga algo que no sabe. El docente es entonces el guía que lo conduce por los caminos desconocidos. Debe transmitirle la seguridad de que llegará. Pero independientemente de adónde llegue, está haciendo un ejercicio que lo inserta en la disciplina. La instancia de la primera corrección es el momento en el que se produce un punto de inflexión. Es aquí donde se juegan las primeras cartas. Se entiende que el docente debe ser por demás reflexivo y contenedor del alumno. Deberá escucharlo con atención, preguntar qué quiso hacer y, reflexionando con él en las sucesivas correcciones, tratar de que reconozca lo que motiva su diseño, que reconozca las intenciones detrás del mismo.

Desde el principio Rossana vivió momentos de incertidumbre. Se entiende que no había otra chance. Ella nunca había estado en un taller. Enfrentada al sulfito esperaba un acto mágico. El tiempo pasa y siente que no conoce la terminología que se utiliza, lo que la aflige. Marcelo la contiene, le dice que no se preocupe. Le plantea que esa tensión de incertidumbre se repetirá a lo largo de toda la profesión. Hace que reflexione sobre las preexistencias, le pide que evoque las sensaciones del terreno y del barrio donde actuarán en este nuevo proyecto. En este momento Marcelo actúa como arrancador. Le da confianza y la ayuda a dar el primer paso, pero desde la reflexión apela a una búsqueda personal. Luego iniciará un proceso en el que paso a paso va alcanzando metas intermedias, basándose siempre en esa guía que son las intenciones. Seguramente llegue a una solución correcta, que verificará. Es entonces donde el docente debe explicitarle al alumno en el estadio en el que se encuentra. Debe mostrarle el logro, pero sobre todo debe transmitirle que alcanzó una plataforma intermedia. Un descanso en el ascenso a la cima. Deberá convencerlo de que redoble la apuesta, que siga subiendo, que no deje de mirar la cima. Esa debe ser su meta. Esto se refleja en el planteo que le hace Marcelo. Él le dice, al comentarle su entrega, que lo que hizo está bien, pero que a partir de ese estadio en que logró dominar sus desafíos, debe aceptar otros nuevos para seguir creciendo, seguir subiendo, seguir buscando.

\section{En búsqueda de la pasión}

Marcelo recordó un ejemplo que aparecía en una de sus valiosas revistas de diseño. Lo hizo mientras dormía, se desveló y no pudo soportar la idea de olvidarlo en la mañana, por lo que se levantó y sacó el ejemplar de su biblioteca. Analizó el ejemplo: era una vivienda del 
Arq. Souto de Moura. Su implantación resolvía el vínculo de los dormitorios con la calle de una manera que podía dar nuevas pistas a Rossana. Al otro día la sorprendió con una nueva alternativa. La corrección culminó pasada la hora de clase, Marcelo hizo participar a todo el grupo. No respondió a las llamadas, nunca miró el reloj. Nada se interpuso, su dedicación fue total. Marcelo es un docente apasionado. Se entiende posible que un docente no comprenda la falta de compromiso del alumno y es común que le traslade la culpa, que manifieste su falta de interés por la carrera. Quizá sea una reacción natural. Seguramente dialogue con sus colegas sobre estas penas que comparten. El tiempo pasará y nada habrá cambiado en su relación con el alumno. Pero si es un docente apasionado, irá a la búsqueda del alumno; hará que se comprometa.

Así como el docente encuentra datos en el alumno para poder leerlo, para poder entenderlo, desde cómo se viste hasta cuántas horas dedica al estudio, también el alumno lee al docente. Seguramente descubra en sus relatos sobre su actividad profesional, sobre la fuerza interior que lo lleva a la búsqueda de la mejor solución sobre el entusiasmo con el que transmite su forma de ver y sentir el diseño; cuando se refiere a la filosofía que lo respalda o cuando se posesiona trasmitiendo la importancia de la ética profesional. Lo hará porque no sólo es un buen profesional, sino porque dejó de ir al recital de John Mayall, uno de sus jazzistas favoritos, que seguramente no volverá a venir. No fue porque la entrega del proyecto lo tenía atrapado. Lo escuchará y lo describirá como un profesional apasionado. El alumno se dará cuenta de su preocupación por el grupo y por su persona, se dará cuenta de sus desvelos. Al darse cuenta de que uno de sus alumnos hace dos semanas que no concurre a clase, pregunta por él al grupo, y quizá luego lo llame por teléfono, le preguntará qué le sucede y le advertirá que si sigue faltando, no tendría tiempo para realizar una buena entrega. El alumno ve que este docente no tiene problema en quedarse fuera de hora, percibe que el teléfono celular le suena y no lo atiende. El tiempo se detiene, nada interrumpe su corrección, sólo lo está atendiendo a él, lo escucha, lo comprende, lo motiva, lo empuja, logra despertar su curiosidad, lo compromete. También le exige que responda de la misma manera y el alumno le da el derecho a hacerlo.

En el transcurso de este trabajo se mencionó la necesidad de conocer al alumno y de ganarse su confianza, de establecer una buena vía de comunicación, de despertar su curiosidad, para de esa manera motivarlo y comprometerlo con la búsqueda de nuevos conocimientos; comprometerlo con la construcción de su propio conocimiento. Esto implica un aprendizaje significativo, un antes y un después. También se analizó la importancia de que conociera la tarea profesional, la manera de trabajar, que la misma se asemeje a esa vocación, a esa futura tarea, la de arquitecto, la de diseñador de interiores. Todo eso está bien, pero falta. Queda algo por transmitir al alumno que termine de sellar a fuego su futuro, que no le permita dormir tranquilo si una idea lo desvela, que lo levante, que lo haga ponerse a trabajar. Incluso que deje de asistir a un evento imperdible, y que acepte dejar de lado cosas que le gustan, en función de hacer lo que más quiere. Esto es estar apasionado. $Y$ tiene mucho que ver con el amor, porque fue seducido, porque nada se interpone. Porque como dice uno de los docentes entrevistados: "Estamos en una carrera, la de arquitectura, que es una belleza. Yo estoy convencido, estoy absolutamente seguro de que los estudios de arquitectura no sólo te sirven para ser, lo que en el colectivo imaginario es un arquitecto, que diseña una cosa, se pone un casco blanco y va a la obra. Es una formación que da una manera de entender el mundo, aunque después termine de gerente en una empresa".

El hablar de esa manera de su propia profesión, de la carrera en la que enseña, el decir que la arquitectura es una belleza, describe el amor y la pasión que siente por ella. 


\section{Conclusiones}

\section{El proceso de Ricardo}

Así como Rossana tuvo su proceso, en lo personal a lo largo de la maestría y sobre todo en la elaboración de esta tesis, yo tuve el mío; algo así, como "El Proceso de Ricardo". Como declaré en la presentación de este trabajo, llegué a la primera clase de este postgrado con una gran incertidumbre y vacío de conocimientos formales. Viví lo mismo que el alumno enfrentado al taller sin conocimientos previos.

Hoy, mirando hacia atrás logro distinguir a docentes y a compañeros que me ayudaron a superar esa etapa, docentes que perfectamente entran dentro de los hallazgos realizados en este trabajo, que se preocuparon por conocer a sus alumnos, que asumieron el compromiso, tanto el de ellos como el de los alumnos, docentes que se preocuparon por motivar al grupo, por no dejar que uno se conformara con la primera idea, aunque correcta, pidiendo un esfuerzo, que nos hicieron salir a la búsqueda de otro autor, analizar desde otra óptica nuestros problemas, valorar los aciertos sin dejar de corregir los errores, siempre desde el lado del apoyo, de la contención, retirando los andamios a medida que ello era posible. Pero por sobre todo despertando nuestra curiosidad, nuestro deseo de aprender, buscando nuestro compromiso, y despertando nuestra pasión, la que nos hizo renunciar a tantas cosas (como Marcelo, renunciamos a varios recitales de John Mayall). Hoy puedo decir que dentro del equipo encontré al docente comprometido, al que puse en el pedestal del ídolo, al psicólogo, al que me acompañó a buscar la cima y al que despertó en mí la pasión.

Y esta es quizá la primera de las conclusiones, la que lleva consigo las siguientes preguntas. ¿Qué habría sucedido con otros docentes? ¿Estaría hoy culminando esta tesis? ¿Me sentiría una persona que aprendió? Y lo que es más importante. ¿Sería una persona que simplemente realizó un aprendizaje significativo, o sería como me siento, otra persona?

\section{Conclusión de la búsqueda}

¿Cuáles son las estrategias que desarrollan aquellos docentes en la enseñanza de diseño que toman en cuenta los conocimientos previos de los estudiantes, en los primeros cursos de las carreras de Arquitectura y Diseño de Interiores?

Ésta es la pregunta que inquieta desde el comienzo de esta tesis. Es la que da inicio a una búsqueda que tiene como objetivo analizar las buenas prácticas que toman en cuenta dichos conocimientos previos, tratando de identificar estrategias para luego filtrarlas, a través del lente personal, para encontrar nuevas categorías teóricas. El recorrido se realiza a través de un marco teórico que nutre a la tesis con un contenido vital. Tiene el sentido de refugiar las ideas personales en los pensamientos en los escritos de los grandes maestros. Sus narraciones son sentidas como sabios consejos que arrojan luz sobre el resto del camino.

¿Cómo podría desarrollarse un trabajo que hace referencia a los conocimientos previos sin mencionar a Ausubel? ¿Se puede hablar de concepciones didácticas sin recurrir a Pozo? ¿Podría estar ausente Perkins si se analiza el aprendizaje reflexivo? ¿Cómo se podría hablar de motivación y deseo sin mencionar a Merieu o Alicia Fernández? ¿O de narración sin aludir a Mc Ewan y a Egan? ¿Cómo se podría hablar de nueva agenda y sobre todo de pasión sin referirse a Edith Litwin? Jackson, Bruner, Sternberg, Piaget, Vygotsky y otros tantos autores podrían seguir citándose, como otros tantos conceptos a los que se hicieron referencia a lo largo de este trabajo.

Resultó una sorpresa encontrar en el análisis del trabajo de campo una relación directa con el marco teórico. Del relato de los docentes entrevistados se percibe, y en algunos casos se afirma, que cuentan con algún tipo de formación pedagógica, ya sea en un contexto formal o en forma autodidáctica. Ellos manifiestan la importancia de los procesos de aprendizaje y los anteponen a los resultados, sin dejar de cumplir con los objetivos del curso. Lo antedicho se relaciona con algo que es fundamental en este trabajo: la importancia del aprendizaje 
significativo, entendiéndolo como un antes y un después, como el proceso del alumno; un alumno que tiene dentro de su historia, dentro de su A.D.N. cultural un cúmulo de conocimientos previos, que al enfrentarse a un nuevo estímulo, a través de la reflexión, sufrirá una alteración de tal magnitud que le provocará un cambio en la genética de su conocimiento. Su conocimiento previo será a partir de ese momento otro. Esta historia se repetirá una y otra vez. Comienza el día que nació, quizá antes y se seguirá construyendo durante toda su vida.

Para que este proceso ocurra el docente deberá establecer con el alumno una muy buena comunicación basada en el conocimiento personal. No deberá despreciar ninguna alternativa que se le presente, un rato libre, un encuentro, una página en Facebook. O como decía uno de los docentes entrevistados, de cosas tan simples como la vestimenta se pueden obtener datos relevantes de la persona. Para conocer al alumno, para comunicarse con él, deberá lograr que exista una confianza mutua, como resultado de la misma y de su capacidad por demostrar su dominio disciplinar y de deslumbrarlo con su conocimiento, el alumno le permitirá enseñarle. Es a partir de ese momento clave, que el docente debe recurrir a los hallazgos realizados. Deberá generar en el alumno la necesidad de aprender, despertar su curiosidad por descubrir, que no se quede con el menú que ya conoce, que busque los platos más sofisticados, que busque nuevas combinaciones de ingredientes que ya maneja. Si logra lo antedicho, hace que el alumno confíe en sí mismo, apoyándolo, haciéndole ver sus errores, pero sobre todo sus aciertos, y que no tenga miedo a equivocarse, entonces se logrará que salga a la búsqueda del conocimiento, que redoble la apuesta, que nunca se quede conforme y que acepte nuevos desafíos. Entonces se logrará que se comprometa y en el mejor de los casos que se apasione.

Se entiende que la tesis podría o quizá debería terminar en el punto anterior. Pero hay otra pregunta que vuelve a inquietar, diferente a la que dio inicio a este trabajo, y que está relacionado con la ética.

Partiendo del supuesto de que lo harán en forma comprometida, ¿deben el docente y la institución conformarse con la transmisión de contenidos o, sin dejar de lado este objetivo, deben preocuparse por la persona? Si se fuera a la búsqueda de la misma, si se le conociera ¿se podría incidir para lograr una sociedad donde las personas tuvieran como objetivo la mejora de sus conciudadanos? ¿Podría la sociedad volver a ser un ágora democrática? ¿Podría transformarse en un gran Taller?

\section{Bibliografía}

- Apolo, J. C. 2006. Talleres: Trazos y señas. Montevideo. Facultad de Arquitectura, Universidad de la República.

- Ausubel, D. et al. 1983. 2da. Ed. Psicología educativa. México D.F. Trillas.

- Bayardo, N. 1990. Hacia una autodidáctica dirigida. Montevideo. Universidad de la República.

- Cyrulnik, B. 2007. De cuerpo y alma. Barcelona. Gedisa Sa.

- Jackson, P. W. 1999. Enseñanzas implícitas. Buenos Aires. Amorrortu.

- Litwin, E. 2003. La Educación a distancia: temas para el debate en una nueva agenda educativa. Buenos Aires. Amorrortu.

- Litwin, E. 2008. Las configuraciones didácticas. Buenos Aires. Paidós.

- Perkins, D. 2003. 3era. Ed. La escuela inteligente. Barcelona. Gedisa.

- Pozo, I. 1996. Aprendices y maestros. Madrid. Alianza.

- Ricobaldi, M. y Ravazzani, C. 2009. http://www.ort.edu.uy/ie/caes/articulo_diciembre09.php 


\section{Bibliografía complementaria}

- Arnheim, R. 1998. 1ra. Ed., 15a. imp. Arte y percepción visual. Madrid. Alianza.

- Arnheim, R. 1978. 2da. Ed. 2001. La forma visual de la arquitectura. Barcelona. Gustavo Gigli.

- Bain, K. 2007. 2da. Ed. Lo que hacen los mejores profesores de universidad. Valencia. Universidad de Valencia.

- Beane, J. A. 2005. La integración del currículum. Madrid. Morata.

- Bruner, J. 1997. La educación, puerta de la cultura. Madrid. Visor.

- Carbonell, J. 2001. La aventura de innovar el cambio en la escuela. Madrid. Morata.

- Camillioni, A. et. al. 1996. Corrientes didácticas contemporáneas. Buenos Aires. Paidós.

- Congreso ACSA/EAAE. 1993. Beginnings in Architectural Education. Washington DC. ACSA.

- Cook, T. D. y Reichardt, C. S. 1986. 3ra. Ed. 1997. Métodos cualitativos y cuantitativos en investigación evaluativa. Madrid. Morata.

- Instituto de Relaciones Culturales con el Exterior. 1968. Bauhaus. Stuttgart. Instituto de Relaciones Culturales con el Exterior.

- Davini, M. C. 1995. La formación docente en cuestión: Política y pedagogía. Buenos Aires. Paidós.

- Fernández, J. E. 21-08-2009. Secretos de familia. El País Cultural N 1030. Montevideo.

- Fernández, A. 1999. La inteligencia atrapada. Buenos Aires. Nueva Visión.

- Kincheloe, J. L. 2001. Hacia una revisión crítica del pensamiento docente. Barcelona. Octaedro.

- Jackson, P. W. 2002. Práctica de la enseñanza. Buenos Aires. Amorrortu.

- Lion, C. 2006. Imaginar con tecnologías. Relaciones entre tecnologías y conocimiento. Buenos Aires. Stella.

- Litwin, E. 1997. El oficio de enseñar. Condiciones y contextos. Buenos Aires. Paidós.

- Maxwell, J. A. 1996. Qualitative Research Design - An Interactive Approach. Sage Publications. Londres.

- Mc Ewan, H. y Egan, K. et al. 1995. La narrativa en la enseñanza, el aprendizaje y la investigación. Buenos Aires. Amorrutu.

- Meirieu, P. 1992 3ra. E. 2002. Aprender, sí. Pero ¿cómo? Barcelona. Octaedro.

- Piaget, J. 1960. El estructuralismo. (Citado en febrero de 2009) Disponible en Internet: http://books.google.com.uy/books?id=Ca3fdvwKpkMC\&dq=el+estructuralismo+comentarios\& source=gbs_summary_s\&cad=0. México. Publicaciones Cruz O. S.A.

- Ricobaldi, M. 2004. Concepciones de la enseñanza: un estudio en torno a docentes experimentados sin formación pedagógica. (tesis de Maestría en Educación). Montevideo. Universidad ORT Uruguay.

- Robinson, K. (http://video.google.com/googleplayer.swf?docid=-9133846744370459335\&hl =es\&fs=true). 
- Sapir, E. 1921. El lenguaje. http://books.google.com.uy/books?id=GNEaa7lh9S0C\&pg=P A47\&lpg=PA47\&dq=el+lenguaje+sapir+ebooks\&source=bl\&ots=is32DWrt6-\&sig=SUU4WxM v7s3rKG9CxF1szvX7bIQ\&hl=es\&ei=IBMYSoDHC8PVIQfKx8zkCw\&sa=X\&oi=book_result\&ct =result\&resnum=1\#PPA7,M1.

- Schön, D. 1992. La formación de profesionales reflexivos. Hacia un nuevo diseño de la enseñanza y el aprendizaje en las profesiones. Madrid. Paidós.

- Sternberg, R. J. 1997. La creatividad en una cultura conformista. Barcelona. Paidós.

- Tuhus, M. 18-02-1996 Connecticut Q\&A: Robert J. Sternberg; Intelligence in All Its Interactive Aspects. Nueva York. New York Times http://www.nytimes.com/1996/02/18/ nyregion/connecticut- $q$-a-robert-j-sternberg-intelligence-in-all-its-interactive-aspects. html?scp=2\&sq=triarchic\%20theory\&st=cse.

- Vygotsky, L. 1995. Pensamiento y lenguaje. Barcelona. Paidós.

- Vygotsky, L. 2000. El desarrollo de los procesos psicológicos superiores. Barcelona. Crítica.

*El artículo se enmarca en la tesis de maestría del autor, dirigida por el Dr. Daniel Germán Ciano. Año 2010.

**Master en Educación, Universidad ORT Uruguay. Diploma en Educación, Universidad ORT Uruguay. Arquitecto, Facultad de Arquitectura, Universidad de la República. 